\title{
Study of some physical and chemical properties of meteorites in Libya
}

\author{
Samir Ahmed Hamouda, Fatima Melad Alshareeif \\ Department of Physics, University of Benghazi, P.O.Box 9480, Benghazi, Libya \\ Email address: \\ dr_s_hamouda@yahoo.ie (S. A. Hamouda), F.alshareeif@gmail.com (F. M. Alshareeif)
}

\section{To cite this article:}

Samir Ahmed Hamouda, Fatima Melad Alshareeif. Study of Some Physical and Chemical Properties of Meteorites in Libya. International Journal of Astrophysics and Space Science. Vol. 1, No. 2, 2013, pp. 7-11. doi: 10.11648/j.ijass.20130102.11

\begin{abstract}
This paper deals with elemental composition analysis of a meteorite sample which was discovered in eastern Libya in Mlodh area at $\left(39.97^{\circ} \mathrm{N}\right)$ and $\left(7.90^{0} \mathrm{E}\right)$ coordinates. Comparisons between elemental concentrations in the meteorite sample and terrestrial rock sample were made. Results showed that the concentrations of elements in the terrestrial rock sample were much higher than the concentrations found in the meteorite sample. Determining the type of meteorite sample remains an extremely difficult matter due to many factors, explanations on these factors are discussed.
\end{abstract}

Keywords: Meteorites, Methods and Technologies of Material Characterization, Chemistry and Physics of Materials

\section{Introduction}

Meteorites are solid bodies from outer space that have fallen to the Earth's surface. They are believed to have originated from the asteroid belt between Mars and Jupiter. Meteorites are remnants in a space as a result of the formation of the solar system [1,2]. The study of meteorites and identifying their element components allow the identification of the chemical structures of the solar system at its formation. This also provides significant data for a wide range of geophysical and space physics studies [3].

The subject of space physics is an important topic in the field of scientific research. It has a global concern and is given the distinctive value of the leading universities in research possibilities and the number of scientific publications related to this field. Among the important topics in the field of space physics is the subject of meteorites.

This paper describes the first study of meteorites at the level of the Libyan Universities, which is a new field of interest for the University of Benghazi. The importance of this study lies in the identification of space science to keep up with other advanced centers in this field and to identify the specialized personal in the field of laboratory analysis and upscale quality.

\section{Description of Sample}

The shape of the meteorite sample is less regular. The approximate dimensions of the meteorite sample are $4.2 \times$ $3.1 \times 2.3 \mathrm{~cm}$, and the original weight was 150 grams. The outside face of the meteorite sample appears black, see Figure1. and the interior of the meteorite sample is silver colored in the presence of intersecting lines on it. Figure2. Shows the internal face of meteorite sample .The density of the meteorite sample is $4.99 \mathrm{~g} / \mathrm{cm}^{3}$.

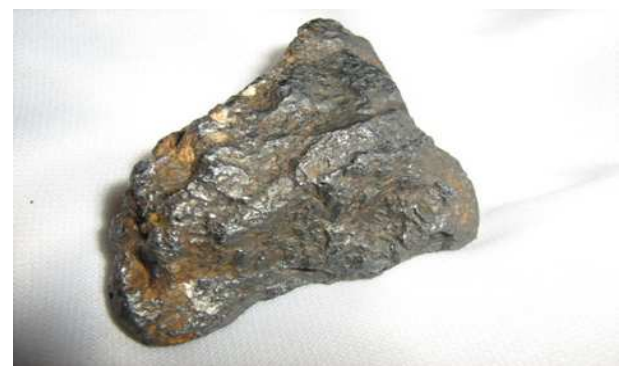

Figure1. Shows the general shape for the meteorite sample.

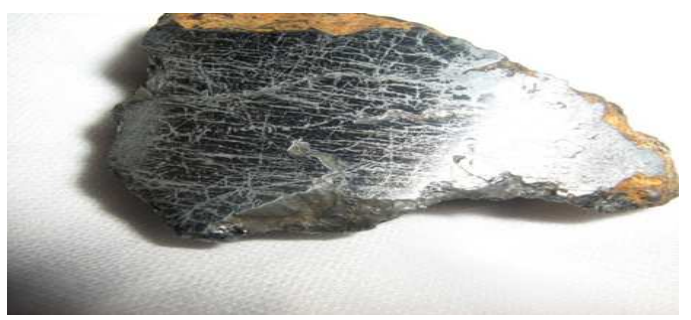

Figure2. Shows the internal features of the meteorite sample after sanding the outer face. 


\section{Method of Analysis}

The purpose of the analysis: is to know the type and classification of the meteorite sample. Sample analysis was conducted in The Nuclear Research Center in Tripoli's Atomic Energy Organization. This was achieved through qualitative measurements of radioactivity $(\alpha, \beta, \gamma)$ of the sample and through analysis of compositional elements in the sample. Elemental composition analysis were carried out using Inductively Coupled Plasma-Optical Emission Spectrometer (ICP-OES) and Total X-Ray Fluorescence (TXRF) systems. Measurements of gamma ray activity in the meteorite sample were carried out using Multi Channel Analyzer (Canberra - DSA1000) connected to Broad Energy-Germanium detector. Measurements of Alpha and Beta activity in the sample were carried out using (Low Background Alpha ,Beta Counter).

\section{Results and Discussion}

The sample preparation and digestion were carried out using acid digestion in the light of the standard methods using (Microwave Furnace). This was carried out once with the addition of some acids such as (HCL - HNO3 - HF), then re-digestion again with the addition of some acid group such as (HNO3 - HCL). Table1. shows the following digestion program in both preparations.

Table1. Shows the digestion program for the meteorite sample.

\begin{tabular}{|c|c|c|c|}
\hline Power (W) & Time (s) & Temp. $\left({ }^{0} \mathrm{C}\right)$ & P (bar) \\
\hline 1200 & 50 & 240 & 60 \\
\hline 1200 & 50 & 240 & 60 \\
\hline
\end{tabular}

Table2. shows radioactivity of the meteorite sample. As can be seen from Table2., the activity of gamma ray is very low and the activity of Alpha and Beta rays are also low and can be considered as laboratory background. Radiation analysis for the meteorite sample is important for the following reasons: The presence of a meteorite in outer space encounters cosmic rays, fast and thermal neutrons, which produce nuclear reactions in the elements of the meteorite sample and some of these elements turned into radioactive isotopes [5]. The presence of radioactivity in the sample was expected, but Table2. shows low radioactivity left in the sample. An explanation of this result can be presented as follows: since the sample has been discovered recently, it means that the sample may have landed on the ground for hundreds or millions of years or even beyond this period. Since radioactivity depends on time (half-life), the low radioactivity found in the sample indicates that the sample may be very old.
Table2. Shows values of $(\alpha, \beta, \gamma)$ activity in the sample

\begin{tabular}{ll}
\hline Type & Specific Activity $(\mathbf{B q} / \mathbf{g})$ \\
\hline Gamma & Very small \\
Gross Alpha & 0.828 \\
Gross Beta & 0.080 \\
\hline
\end{tabular}

Table3. Shows the concentration of elements in the meteorite sample. As can be seen from Table3. that the highest concentration (ppm) in the sample tend to iron $\mathrm{Fe}(\%$ $81)$, followed by a $\mathrm{Ti}(\% 5.7)$, followed by a $\mathrm{Mg}(\% 5.1)$ and there are many elements that have been identified through the use of system ICP-OES .The proportions of different concentrations in the analysis reflect the sensitivity of ICP-OES system. The TXRF system was used to determine the concentrations of some elements in the sample and compare them with the results of ICP-OES. It can be seen from the results that there is no significant difference between the two systems.

To determine whether the sample is a meteorite or other terrestrial rock, a comparison between elements concentration in the sample and their concentrations in a terrestrial rock sample was made. As can be seen from Table4. that the concentrations of the elements in the terrestrial rock sample were much higher than the concentrations found in the sample and this is an indication that the sample is not a terrestrial rock. More accurate Comparisons can be made, taking the ratio of concentrations of elements to iron in both samples (meteorite and terrestrial rock). To make a comparison between elements concentrations (ppm) in terrestrial rocks and a meteorite sample, TXRF analytical results conducted on a terrestrial rock sample at The Nuclear Research Centre were used [4]. Table4. shows the concentrations ( $\mathrm{ppm})$ in meteorite and terrestrial rock samples.

Table3. Data analysis for the meteorite sample using both ICP-OES and TXRF systems.

\begin{tabular}{llll}
\hline ICP- OES & & & TXRF \\
\hline Element & Concentration & Concentration & \\
& ppm & $\%$ & Concentration \% \\
Li & 65 & 0.0065 & \\
Na & 625 & 0.0625 & \\
Mg & 51800 & 5.18 & \\
K & 294 & 0.0294 & \\
Ca & 593 & 0.0593 & 6.0 \\
Ti & 57333 & 5.73 & 1.2 \\
Cr & 13.728 & 0.00137 & 83 \\
Mn & 15225 & 1.5225 & \\
Fe & 814008 & 81.4008 & \\
Co & 345.4 & 0.03454 & \\
\hline & & & \\
\hline & & & \\
\hline
\end{tabular}




\begin{tabular}{llll}
\hline ICP- OES & & & TXRF \\
\hline Ni & 26.86 & 0.00268 & \\
Zn & 592 & 0.0592 & 0.049 \\
Al & 27456 & 2.7456 & \\
Ga & 1864 & 0.1864 & \\
Pb & 5304 & 0.5304 & \\
Bi & 250 & 0.0250 & \\
Sr & 38.4 & 0.0038 & \\
Ba & 2808 & 0.2808 & \\
B & 1373 & 0.1373 & \\
Ag & 595 & 0.0595 & 0.09 \\
Cd & 203 & 0.0203 & 0.03 \\
P & 811 & 0.0811 & \\
Sc & 62 & 0.0062 & \\
La & 1248 & 0.1248 & \\
V & 2758 & 0.2758 & 0.30 \\
Si & 1092 & 0.1092 & \\
W & 38.1 & 0.00381 & \\
Tl & $\square 0.02$ & $\square 0.000624$ & \\
Ge & $\square 0.02$ & $\square 0.000624$ & \\
Cu & $\square 0.02$ & $\square 0.000624$ & \\
In & $\square 0.02$ & $\square 0.000624$ & \\
\hline & & & \\
\hline
\end{tabular}

\begin{tabular}{lll}
\hline & Meteorite sample & terrestrial rock sample \\
\hline Sr & 38.4 & 457.27 \\
Ba & 2808 & 30071.88 \\
B & 1373 & - \\
Ag & 595 & - \\
Cd & 203 & - \\
P & 811 & - \\
Sc & 62 & - \\
La & 1248 & - \\
V & 2758 & - \\
Si & 1092 & - \\
W & 38.1 & - \\
TI & ]0.02 & - \\
Ge & 国0.02 & - \\
Cu & ]0.02 & - \\
In & ]0.02 & \\
\hline
\end{tabular}

To determine the proportion of elements in both samples, the proportion of each element in the sample to the proportion of iron Fe were calculated. Table 5. shows the ratio of concentrations of elements to the ratio of concentrations of elemental iron in both samples.

Table 5. Shows values for the proportion of elements to iron in both samples.

Table 4. Shows the concentrations (ppm) in meteorite and terrestrial rock

\begin{tabular}{lll}
\hline & Meteorite sample & terrestrial rock sample \\
\hline & ICP-OES & TXRF \\
Element & Concentration & \\
& $($ ppm) & Concentration (ppm) \\
Li & 65 & - \\
Na & 625 & 203592.00 \\
Mg & $\mathbf{5 1 8 0 0}$ & 28942.00 \\
K & 294 & 7498.00 \\
Ca & 593 & 45257.59 \\
Ti & 57333 & - \\
Cr & 13.728 & - \\
Mn & 15225 & 1607.43 \\
Fe & $\mathbf{8 1 4 0 0 8}$ & 120016.97 \\
Co & 345.4 & - \\
Ni & 26.86 & 505.19 \\
Zn & 592 & 223.64 \\
Al & 27456 & - \\
Ga & 1864 & - \\
Pb & 5304 & - \\
Bi & 250 & - \\
\hline
\end{tabular}

\begin{tabular}{lll}
\hline Element/Fe & meteorite sample & $\begin{array}{l}\text { terrestrial rock } \\
\text { sample }\end{array}$ \\
\hline $\mathrm{Li}$ itio & 65 & - \\
$\mathrm{Na} / \mathrm{Fe}$ & 0.0008 & 1.69 \\
$\mathrm{Mg} / \mathrm{Fe}$ & 0.0636 & 0.24 \\
$\mathrm{~K} / \mathrm{Fe}$ & 0.0004 & 0.06 \\
$\mathrm{Ca}$ & 0.0007 & 0.38 \\
$\mathrm{Ti}$ & 57333 & - \\
$\mathrm{Cr}$ & 13.728 & - \\
$\mathrm{Mn} / \mathrm{Fe}$ & 0.0187 & 0.01 \\
$\mathrm{Fe} / \mathrm{Fe}$ & 1.00 & 1.00 \\
$\mathrm{Co}$ & 345.4 & - \\
$\mathrm{Ni} / \mathrm{Fe}$ & 0.00003 & 0.004 \\
$\mathrm{Zn} / \mathrm{Fe}$ & 0.00073 & 0.002 \\
$\mathrm{Al}$ & 27456 & - \\
$\mathrm{Ga}$ & 1864 & - \\
$\mathrm{Pb}$ & 5304 & - \\
$\mathrm{Bi}$ & 250 & - \\
$\mathrm{Sr} / \mathrm{Fe}$ & 0.00005 & 0.004 \\
$\mathrm{Ba} / \mathrm{Fe}$ & 0.0034 & - \\
$\mathrm{B}$ & 1373 & \\
\hline
\end{tabular}




\begin{tabular}{lll}
\hline $\begin{array}{l}\text { Element/Fe } \\
\text { ratio }\end{array}$ & meteorite sample & $\begin{array}{l}\text { terrestrial rock } \\
\text { sample }\end{array}$ \\
\hline $\mathrm{Ag}$ & 595 & - \\
$\mathrm{Cd}$ & 203 & - \\
$\mathrm{P}$ & 811 & - \\
$\mathrm{Sc}$ & 62 & - \\
$\mathrm{La}$ & 1248 & - \\
$\mathrm{V}$ & 2758 & - \\
$\mathrm{Si}$ & 1092 & - \\
$\mathrm{W}$ & 38.1 & - \\
$\mathrm{TI}$ & $\square 0.02$ & - \\
$\mathrm{Ge}$ & $\square 0.02$ & - \\
$\mathrm{Cu}$ & $\square 0.02$ & - \\
In & $\square 0.02$ & - \\
\hline
\end{tabular}

It is clear from Table5. that the ratio of element concentrations to iron $\mathrm{Fe}$ in the terrestrial rock sample are much higher than in the meteorite sample. This is another indication that reinforces the belief that this sample is a meteorite. It can be concluded from the preceding discussion that the characterization of this sample are not compatible with the terrestrial rock. This result indicates that this sample does not belong to the earth and that the source is outer space.

Determining the type of meteorite sample remains an extremely difficult matter and is the subject of controversy at the global level. The reason for this goes back to the different sources of meteorites[6-8], some are solar meteorites, others including lunar and Martian[9]. Each type of meteorites is different in element concentrations. This is due to different speeds of entry into the Earth's atmosphere and the degree of melting before colliding with the earth surface. Also the extent of interaction with environment surroundings, climate factors of erosion and oxidation over thousands and millions of years. A meteorite's composition can also be altered by weathering after it falls [10].

According to the comprehensive study about the types of meteorites classification with respect to the concentrations of the elements [11], the types of meteorites rating falls within the average concentrations of elements in most of the meteorites that have been identified. For example, the concentrations of the elements $\mathrm{O}, \mathrm{Si}, \mathrm{Fe}$ is greater than $10 \%$. Concentrations of elements: $\mathrm{Mg}, \mathrm{S}, \mathrm{Ca}, \mathrm{Ni}$ between (1-10\%). Concentrations of elements: $\mathrm{Al}, \mathrm{Na}, \mathrm{Cr}, \mathrm{Mn}$ ranges (0.1-1\%). Concentrations of elements: $\mathrm{P}, \mathrm{Cl}, \mathrm{K}, \mathrm{Co}, \mathrm{Ti}, \mathrm{Zn}, \mathrm{Cu}$ between (0.01-0.1\%). All element concentrations in other meteorites are less than $0.01 \%$. This study shows variation in the values of the concentrations of elements in most of the meteorites that have been identified. Given average values for element concentrations. These differences in concentration values may also be due to the diversity of analysis systems, sensitivity and accuracy in the analysis of trace elements.

\section{Conclusion}

This is the first study of its kind at the level of the Libyan Universities, which is unique to the University of Benghazi. Laboratory analysis was provided and concentrations of elements in the meteorite sample have been identified. This was done using local analysis systems, in The Nuclear Research Centre, Tripoli- Libya. This analysis added to the value of study a great moral importance where such analysis were developed in Libya. The importance of this study rests in the identification of astrophysics and space science to keep up with the leading research centers and universities in this field. Also encouraging young graduates to engage in such studies, which require scientific backgrounds in physics, chemistry and math all combined.

\section{Acknowledgement}

We would like to express our gratitude to the Head of The Nuclear Research Center in Tripoli's Atomic Energy Organization for his kind support. We are also grateful to Dr. Rafa Alzaroog for supplying us with the meteorite sample and special thanks to Dr. Hamza Briek Hamza for carrying out the analysis and for his fruitful discussions about this work.

\section{References}

[1] Web: MexicoGemstones.com

[2] John D. O'Keefe et al. " Planetary Cratering Mechanics"., Journal of geophysical Research, Vol.98., No .E9., 1993., $17,011-17,028$

[3] G. A. EIBY., "A Survey of the Tektite Problem ”., New Zealand Journal of Geology and Geophysics ., 2., 1959., $183-94$

[4] A. A. Altalhy., MSc. Thesis (unpublished), University of Benghazi, Libya (2007).

[5] G. J. Taylor., Gamma Rays, Meteorites, Lunar Samples, and the Composition of the Moon"., Planetary Science Research Discoveries.,

(2005): http://www.psrd.hawaii.edu/Nov05/MoonComposition .html

[6] R. L. Korotev et al., " Compositions of three lunar meteorites: Meteorite Hill 01210, Northeast Africa 001, and Northwest Africa 3136"., Lunar and Planetary Science XXXVI., (2005)., Abstract \# 1220

[7] R. L. Korotev., “ Composition of Lynch 002 Lunar Meteorite"., 76th Annual Meteoritical Society Meeting., (2013)., Abstract \# 5021

[8] A. Wittmann et al., " Trace Elements Composition of Impact Melts In Lunar Meteorite Shisr 161"., 76Th Annual Meteoritical Society Meeting., (2013)., Abstract \# 5262

[9] M. Anand et al., “ Fe Isotopic Composition of Martian Meteorites"., Lunar and Planetary Science XXXVI., (2005)., Abstract \# 1859 
[10] L. R. Nittler et al., "Bulk element compositions of meteorites: a guide for interpreting remote-sensing geochemical measurements of planets and asteroids"., Antarct. Meteorite Res., 17, (2004), 233-253
[11] B. Mason., "Data of Geochemistry" Sixth Edition, Michael Fleischer, Technical Editor, Geological Survey Professional Paper 440-B-1, 1979, (B1-B132) 